\title{
The Influence of the Thermal Treatment of Hydroxylapatite Scaffolds on the Physical Properties and the Bone Cell Ingrowth Behaviour
}

\author{
Alexander Woesz ${ }^{1}$, Monika Rumpler ${ }^{1}$, Inderchand Manjubala ${ }^{1}$, Christine Pilz ${ }^{1}$, Franz Varga ${ }^{2}$, \\ Juergen Stampfl ${ }^{3}$ and Peter Fratzl ${ }^{1}$ \\ ${ }^{1}$ Max Planck Institute of Colloids and Interfaces, Dept. of Biomaterials, Potsdam, Germany \\ ${ }^{2}$ Ludwig Boltzmann Institute of Osteology at the Hanusch Hospital of WGKK and AUVA \\ Trauma Centre Meidling, 4th Medical Department, Hanusch Hospital, Vienna, AUSTRIA \\ ${ }^{3}$ Institute of Materials Science and Technology, University of Technology, Vienna, Austria
}

\begin{abstract}
The material bone consists of a biopolymer matrix (collagen) reinforced with mineral nanoparticles (carbonated hydroxylapatite), forming a natural composite which builds up a dense shell on the exterior and a network of struts with a mean diameter of $200 \mu \mathrm{m}$ in the core of many bones. The architecture of the foamy inner part of bones (spongiosa) is determined by loading conditions. The architecture strongly influences the mechanical properties of cellular solids together with the apparent density and the material it consists of. In addition, the ingrowth of bone cells into porous implants depends on pore size, size distribution and interconnectivity. From this it is clear that the possibility to design the architecture of a bone replacement material is beneficial from a biological as well as a mechanical point of view. Our approach uses rapid prototyping methods, ceramic gelcasting and sintering to produce cellular structures with designed architecture from hydroxylapatite and other bioceramics.

The influence of sintering temperature and atmosphere on the physical properties of these scaffolds was investigated with $\mathrm{x}$-ray diffraction and scanning electron microscopy. Furthermore, the cell ingrowth behaviour was determined in cell culture experiments, using the praeosteoblastic cell line MC3T3-E1, derived from mouse calvariae. The cell ingrowth behaviour was evaluated during a culture period of two and three weeks, by light microscopy and afterwards by histology after embedding and Giemsa-staining.

The phase composition of the material was found to change with increasing sintering temperature and its surface characteristics was influenced by the sintering atmosphere. These changes also affected the cell ingrowth behaviour. In some experiments, the osteoblasts-like cells were found to cover the whole external and internal surface of the scaffold. The cells produced extracellular matrix consisting of collagen, which eventually filled nearly all the pores. In particular, the cells had the tendency to fill any crack or opening in the scaffolds, and to generally smooth the surfaces.

In conclusion, rapid prototyping and ceramic gelcasting allows the freeform fabrication of porous bioceramics with controlled architecture. Such structures made of hydroxylapatit were found to support the growth of mouse osteoblasts.
\end{abstract}

\section{WHY CELLULAR IMPLANTS WITH CONTROLLED ARCHITECTURE?}

For several applications porous implants are beneficial compared to the dense ones, the reasons for this being manifold. In the first place, the cell ingrowth into the implants fixes it mechanically, thus even increasing the implant's strength [1]. In order to ensure the possibility 
for the cells to grow into and the cell nutrients to flow into the pore, the diameter of the pores must not fall below a certain value (in literature optimal diameters between $150 \mu \mathrm{m}$ and $500 \mu \mathrm{m}$ are mentioned [2-6]). Secondly, if the material is to be resorbable, a maximum wall thickness should not be exceeded in order to allow the osteoclasts to resorb the material and subsequently to enable the osteoblasts to replace it by the body's own bone material. With these boundary conditions, a minimum pore diameter and a maximum wall thickness, a certain maximum value for the apparent density of the porous structure is predetermined. In a previous study we investigated the influence of the architecture on the mechanical properties of cellular structures at given apparent density and showed that it is possible to adjust the strength and stiffness as well as the defect tolerance of a unit cell based cellular structure within a wide range just by changing the architecture [7].

Hence, from both biological and mechanical requirements it is clear that it is beneficial to have the possibility to adjust the architecture of a cellular implant.

\section{PRODUCTION OF HYDROXYLAPATITE SCAFFOLDS}

The first step towards a cellular implant with designed macro-porosity was the virtual design of a casting mould for this implant using computer aided design (CAD) programs. We used a solid modelling program called Pro/Engineer (PTC, Needham, MA, USA) to virtually put together simple three dimensional objects like cylinders and cuboids to form a structure as can be seen in Fig. 1.

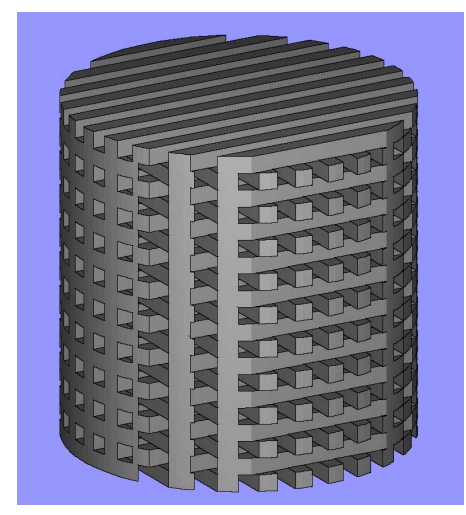

Figure 1. Virtual structure designed with CAD program. This structure was reproduced in hydroxylapatite.

The virtual file, provided with a covering, was saved in STL file format and imported into the software controlling the rapid prototyping machine. In this software the structure was decomposed into thin layers, which were afterwards successively built in the rapid prototyping machine. While we used to use a digital light processing method to produce the casting moulds from resin [8], we changed to Solidscape Modelmaker (Solidscape, Inc., Merrimack, NH, USA), which is a three dimensional wax printer using two different kinds of waxes for the production of the casting mould. The mould consisted of the blue building wax while the red support wax, which was removed after the building job was finished, was necessary to produce overhanging features within the structure. The principle of this method is depicted in Fig. 2. 


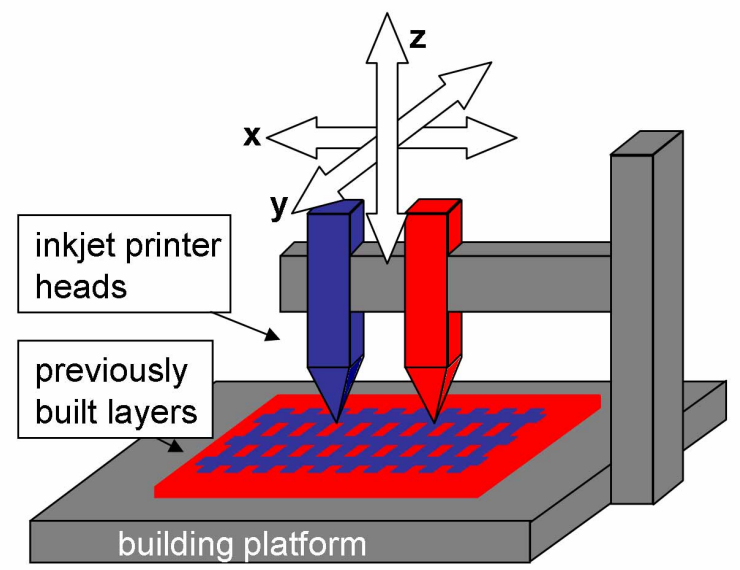

Figure 2. Principle of inkjet printing, Solidscape Modelmaker II

The advantage of this system compared to the digital light processing based system was the fact that the mould material is wax instead of resin, which has a lower strength and stiffness, and a lower melting point, resulting in lower stress in the green part during demoulding.

The mould produced as described was filled with a ceramic suspension, which was produced by mixing together water, monomers, a dispersion agent and artificial hydroxylapatite powder (Plasma Biotal Ltd., Tideswell, North Derbyshire, UK). Shortly before casting, a catalyst and initiator were added. Casting took place within a vacuum casting device, in order to properly fill the mould with the ceramic suspension. After the filled mould was removed from the casting device, it was put into a furnace, and the temperature was slowly increased up to $60{ }^{\circ} \mathrm{C}$, in order to polymerise the monomers within the suspension and thus give the green part some strength [911]. Further elevation of the temperature caused the water to dry, the mould to melt and finally the ceramic green part to sinter. Sintering temperature was varied between $1200{ }^{\circ} \mathrm{C}$ and $1350{ }^{\circ} \mathrm{C}$ in steps of $50{ }^{\circ} \mathrm{C}$. Some of the scaffolds were sintered in nitrogen with a partial pressure of about 100 mbar, some of them were exposed to a post-sintering procedure in air, too.

The scaffolds obtained by the procedure described above can be seen in Fig. 3. The differences in colour (the pink scaffolds were obtained by sintering in nitrogen, the blue ones by postsintering in air) originate from manganese traces within the raw material [12].

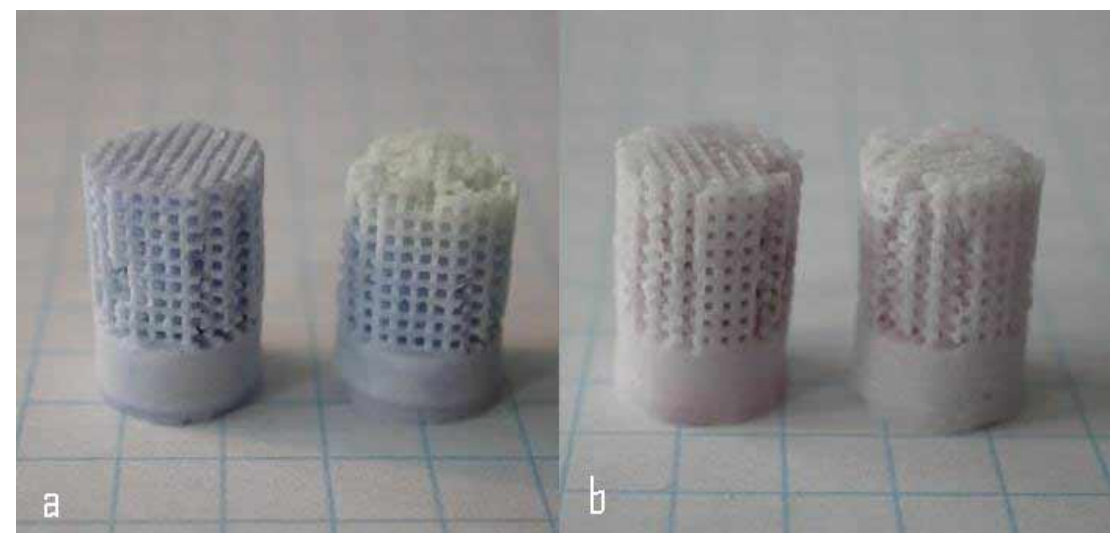

Figure 3. Scaffolds made from hydroxylapatite, a) and b) sintered in nitrogen at $1250^{\circ} \mathrm{C}$ and a) post-sintered in air at $1200^{\circ} \mathrm{C}$. The edge length of the squares in the background is $5 \mathrm{~mm}$. 


\section{PHYSICAL CHARACTERISATION OF THE SCAFFOLDS}

The first investigation was performed using an X-ray powder diffractometer (D8 x-ray diffractometer, Bruker AXS Ltd., Meadowside, Cheshire, UK) after small fragments of the scaffolds have carefully been pulverised. The comparison between the raw material and the material sintered at $1200^{\circ} \mathrm{C}$ (Fig. 4) reveals decomposition of the hydroxylapatit into tricalciumphosphate (TCP), tetracalciumphosphate and calcium oxide, phases, whose bioresorbability is higher then the bioresorbability of the hydroxylapatite raw material [13], following the reactions given below:

$$
\begin{aligned}
& \mathrm{Ca}_{10}\left(\mathrm{PO}_{4}\right)_{6}(\mathrm{OH})_{2} \rightarrow \mathrm{Ca}_{3}\left(\mathrm{PO}_{4}\right)_{2}+\mathrm{Ca}_{4} \mathrm{P}_{2} \mathrm{O}_{9} \\
& \mathrm{Ca}_{10}\left(\mathrm{PO}_{4}\right)_{6}(\mathrm{OH})_{2} \rightarrow \mathrm{Ca}_{3}\left(\mathrm{PO}_{4}\right)_{2}+\mathrm{CaO}
\end{aligned}
$$

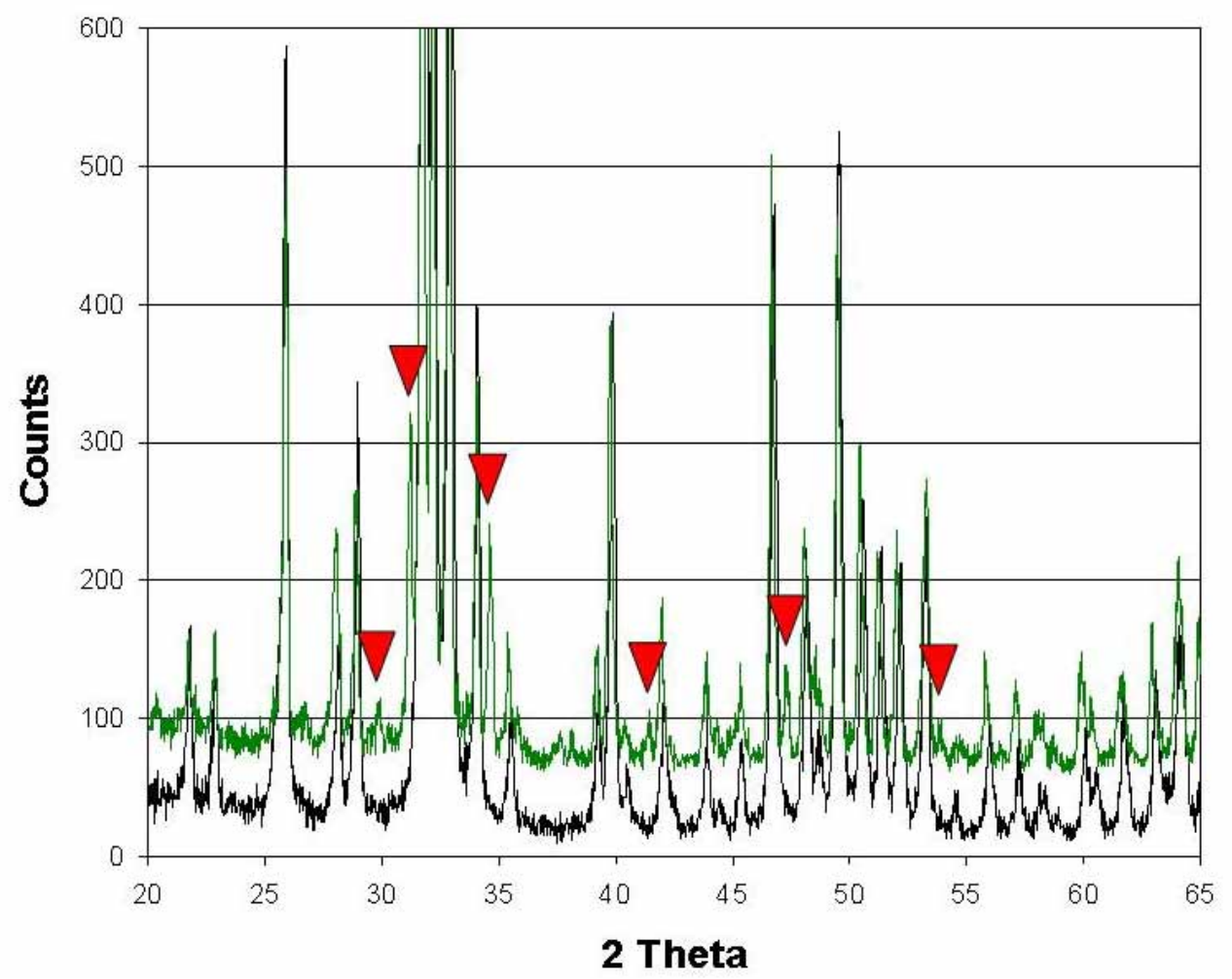

Figure 4. Overlaid X-Ray diffraction patterns of the raw material and the pulverised sample sintered at $1200{ }^{\circ} \mathrm{C}$. The red triangles point at the new peaks arising during sintering.

When comparing the diffraction pattern of samples sintered at $1200^{\circ} \mathrm{C}$ and $1350^{\circ} \mathrm{C}$, the shift of the TCP-peak due to transformation of $\beta$-TCP into $\alpha$-TCP is the only detectable change. Comparing samples sintered at a certain temperature, but in different atmospheres does not reveal any differences in phase composition.

This seems to be in contradiction to the results obtained with scanning electron microscopy (SEM). In Fig. 5 the surfaces of two scaffolds sintered at the same temperature, but in different atmospheres can be seen. 


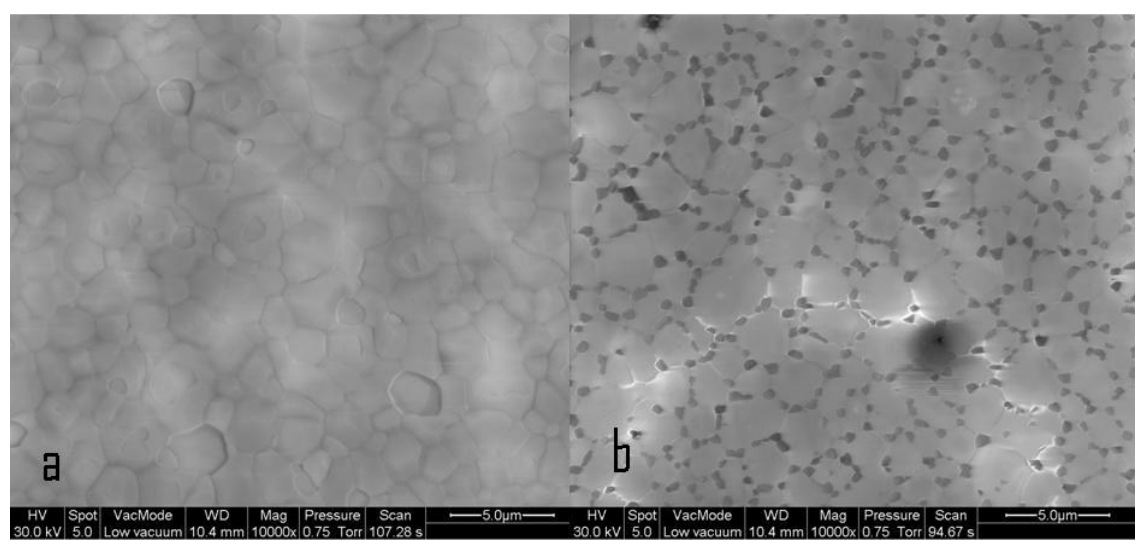

Figure 5. SEM images of the surfaces of two scaffolds sintered at $1250^{\circ} \mathrm{C}$ in a) nitrogen and b) nitrogen followed by air, respectively.

Two possible explanations for the apparent discrepancy with the results of x-ray diffraction are conceivable: the dark regions on the surface of the scaffold sintered in air could be a new phase which exists only on the surface and is therefore not detected with x-rays, or, the more likely possibility, a phase which is present on both scaffolds breaks out during the sintering in air thus causing the dark regions to appear.

\section{CELL CULTURE EXPERIMENTS}

The scaffolds were immersed in cell culture medium and seeded at a density of $8 \times 10^{6}$ praeosteoblastic MC3T3-E1 cells per scaffold. During the culture period of two and three weeks respectively, the cell proliferation and growth, especially ingrowth into the scaffold, were observed with light microscopy. After the culture period, the scaffolds were embedded in resin, cut, grinded, polished and stained with Giemsa.

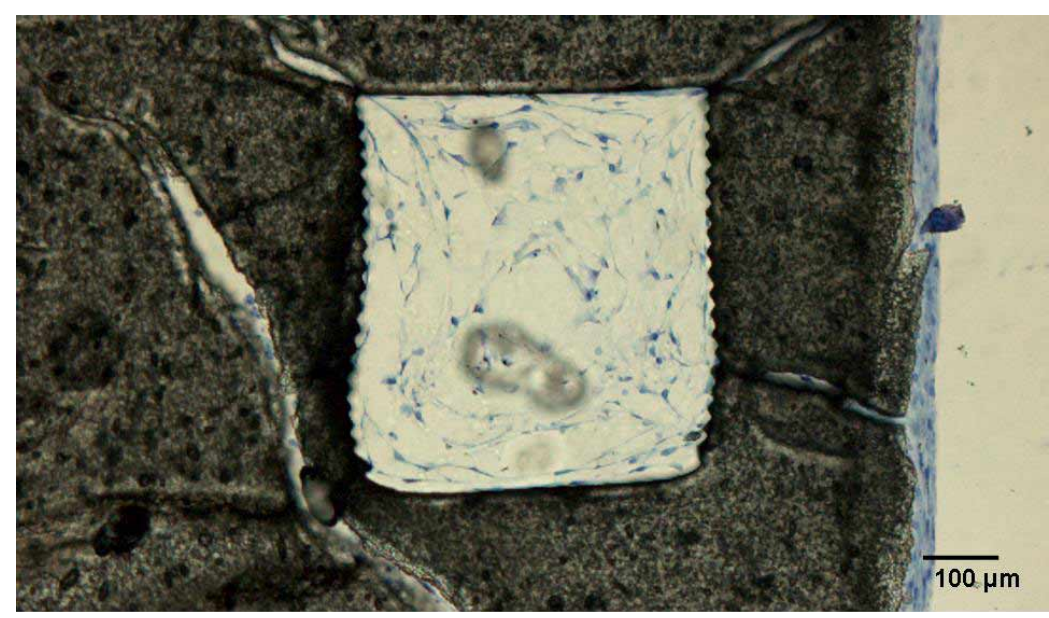

Figure 6. Histological section through a scaffold (grey/black) embedded in resin. The cells, which cover the surfaces, are stained with giemsa (blue) and are embedded in a self-produced matrix consisting of collagen. 
Observation of the cell growth during culture against the sintering temperature and atmosphere qualitatively revealed an optimal sintering temperature of $1300^{\circ} \mathrm{C}$ and showed that the postsintering in air is beneficial as far as cell ingrowth is concerned. Trying to strengthen this impression by quantitative analysis of the histological sections failed due to the varying structural quality of the scaffolds and the high heterogeneity of the cell proliferation.

Nevertheless, in some scaffolds, a complete filling of the pores and a seamless coverage of the inner and outer surfaces of the scaffold was obtained. In particular, the tendency of the cells to fill any crack and to smooth the surface roughness was eye-catching (compare Fig. 6).

\section{CONCLUSIONS}

It is obvious that using the production method for hydroxylapatite scaffolds introduced above enables one to adjust the architecture of the scaffold within a wide range, a possibility which is beneficial both for optimisation of the biological properties like cell ingrowth, nutrition and resorption and for the adaptation of the mechanical properties of the scaffold. The suitability of these scaffolds as substrates for cell culture was proven, physical characterisation and cell culture experiments showed that the thermal history of the scaffolds strongly influences the applicability of the material as bone replacement material.

\section{REFERENCES}

1. J. Vuola, R. Taurio, H. Goransson and S. Asko-Seljavaara, Biomaterials, 19, 223, (1998)

2. B. S. Chang, C. K. Lee, K. S. Hong, H. J. Youn, H. S. Ryu, S. S. Chung and K. W. Park, Biomaterials, 21, 1291, (2000)

3. O. Gauthier, J. M. Bouler, E. Aguado, P. Pilet and G. Daculsi, Biomaterials, 19, 133, (1998)

4. J. Klawitter, A basic investigation of bone growth in porous materials, $\mathrm{PhD}, \mathrm{Clemson}$ University, Clemson, 1979

5. Y. Kuboki, H. Takita, D. Kobayashi, E. Tsuruga, M. Inoue, M. Murata, N. Nagai, Y. Dohi and H. Ohgushi, Journal of Biomedical Materials Research, 39, 190, (1998)

6. S. Kujala, J. Ryhänen, A. Danilov and J. Tuukkanen, Biomaterials, 24, 4691, (2003)

7. A. Woesz, J. Stampfl and P. Fratzl, Advanced Engineering Materials, 6, 134, (2004)

8. A. Woesz, M. Rumpler, J. Stampfl, F. Varga, N. Fratzl-Zelman, P. Roschger, K. Klaushofer and P. Fratzl, Materials Science and Engineering C, in press, (2004)

9. M. A. Janney, O. O. Omatete, C. A. Walls, S. D. Nunn, R. J. Ogle and G. Westmoreland, Journal of the American Ceramic Society, 81, 581, (1998)

10. O. O. Omatete, M. A. Janney and S. D. Nunn, Journal of the European Ceramic Society, 17, 407, (1997)

11. F. S. Ortega, P. Sepulveda and V. C. Pandolfelli, Journal of the European Ceramic Society, 22, 1395, (2002)

12. P. D. Johnson, J. S. Prener and J. D. Kingsley, Science, 141, 1179, (1963)

13. S. Yamada, D. Heymann, J. M. Bouler and G. Daculsi, Biomaterials, 18, 1037, (1997) 